\title{
A Message from the President
}

\author{
by Ronald M. Bremner, M.D., Saskatoon
}

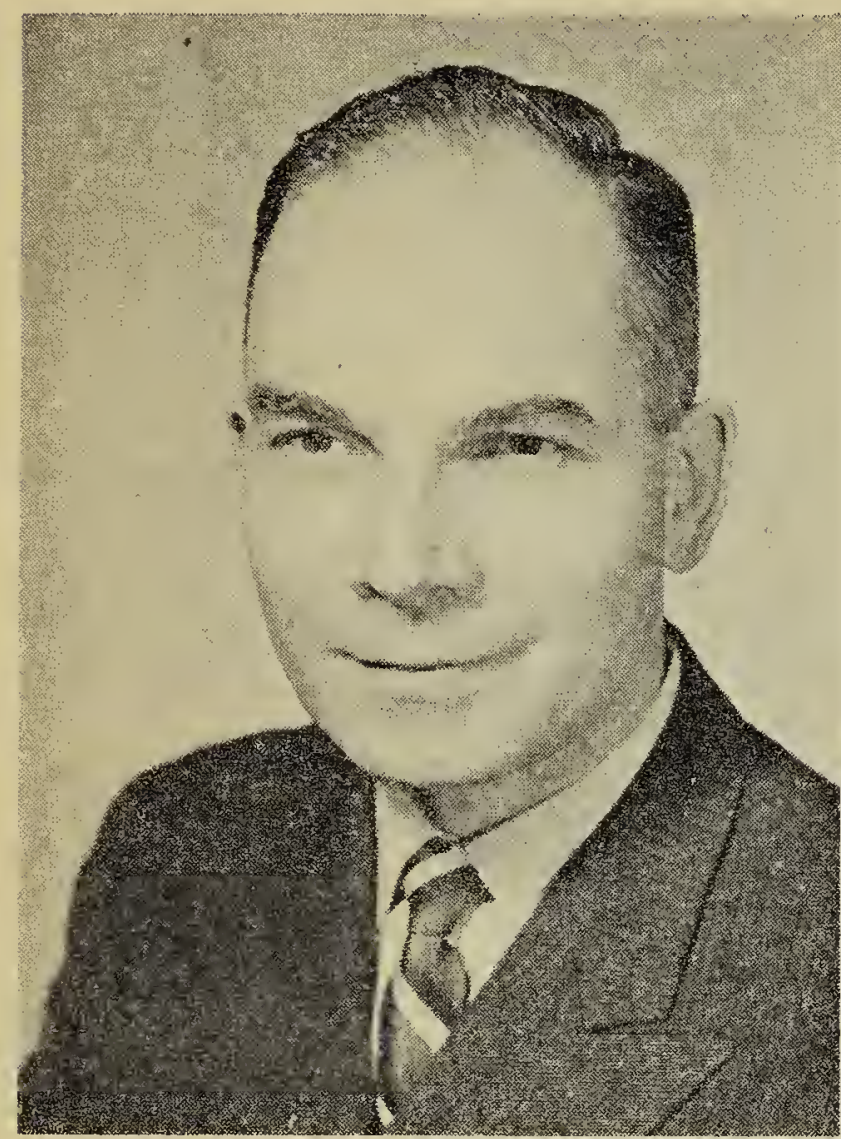

During the past several years this page has become a tradition for readers of the Blue Jay. Your new president has no pretense of offering any profound observations or suggestions for the members of the Saskatchewan Natural History Society, but perhaps the major function of this annual message is to present a photo so that the president may at least be recognizable to all those who receive our quarterly journal.

At the outcet I offer my thanks to those at the annual meeting who have honored me by election to this office. I am humbled by the confidence which has been placed in me but offer my immediate assurance that I shall do my best to prove worthy of the responsibilities which I inherit. I cannot hope to attain the success achieved by many eminent predecessors but I can be most grateful to the members for providing me with such a strong and proven executive. It is no secret that certain dedicated individuals have long been and shall continue to be the indispensable nucleus of our association.

My own knowledge of and membership in the Society encompasses a short period of merely six years. Except for the missionary zeal of Dr.
Stuart Houston, such an exalting event in my life might not have occurred. This personal experience merely emphasizes the fact that the strength and success of our organization is dependent upon the individual effort of each of us. Such effort can and should be directed towards increasing our membership, and would be the most significant support which could be given your executive during the coming year by all who read this message. Many others still outside of our Society share with us a common concern for conservation and preservation of our wilderness resources. One such large group of Saskatchewan citizens are now members of the Saskatchewan Fish and Game League, a responsible organization which has recently had to discontinue the publication of its own periodical. The Blue Jay would be a very worthy medium for such persons and we invite their association by means of membership in the Saskatchewan Natural History Society. The happy fusion of efforts towards conservation is also exemplified by the many D.N.R. personnel who play increasingly important roles in our executive and committees.

Probably the second most important means of supporting your Society is by contributions to the Blue Jay. The continued recording of accurate original observations by amateurs is not only desirable but remains essential in the great scope of nature lore. This journal should also be an effecttive forum for opinions and recommendations relative to any aspect of our very broad interests, and such letters to the editor would be welcome.

The third desideratum of active membership would be individual support of similar organizations, especially the Canadian Audubon Society. T'he recent re-organization of the Canadian Audubon Society which was confirmed by its first annual meeting in November is an event which we can all unanimously welcome by offering our greatest good wishes. It represents an acknowledgment by government of the basically altruistic motivation of this national association with which we are affiliated as a Society. 